\title{
MAP OF THE UTILIZATION OF SOCIAL MEDIA IN FORMING STUDENT LITERATION CULTURE IN MAKASSAR
}

\author{
Himayah $^{1}$ \\ 1 Jurusan Ilmu Perpustakaan, Universitas Islam Negeri Alauddin Makassar \\ Correspondence email: mayaperpus@gmail.com
}

\begin{abstract}
This study aims to see a map of social media use in shaping a literacy culture among students in Makassar. The ease of accessing information sources, copying and pasting information to other places, or sharing information with other parties, has changed students' literacy habits. Using a quantitative approach, this study distributes questionnaires to students via the google docs link. A total of 200 students who have been willing to fill out and return this research questionnaire. The result of this research found that social media has become a necessity for students, especially used for chatting with their friends. Apart from communicating, social media is also used for education, literacy, and fun. Regarding reading and writing literacy habits, social media provides easy access to information providers, so that students use it to meet their needs without having to bother, especially to re-read and check reading material. The variety of information changes rapidly, making students feel that they are sufficient to read news headlines without having to read the entire contents of the information. Likewise, regarding the credibility of news sources, it is not an important thing for students to pay attention to. This shows that the habit of using social media has not been able to help improve literacy skills among students.
\end{abstract}

Keywords: Social Media, Literacy, Digital Information

\begin{abstract}
Abstrak
Penelitian ini bertujuan melihat peta pemanfaatan media sosial dalam membentuk budaya literasi di kalangan mahasiswa di Makassar. Kemudahan dalam mengakses sumber informasi, menyalin dan menempel informasi ke tempat lain, atau membagikan informasi kepada pihak lain, telah mengubah kebiasaan mahasiswa dalam berliterasi. Dengan menggunakan pendekatan kuantitatif, penelitian ini menyebarkan angket kepada mahasiswa melalui link google docs. Sebanyak 200 mahasiswa yang telah bersedia mengisi dan mengembalikan angket penelitian ini. Hasik penelitian ini menemukan bahwa media sosial sudah menjadi kebutuhan mahasiswa, terutama digunakan untuk mengobrol dengan teman-teman mereka. Selain berkomunikasi, media sosial juga digunakan untuk pendidikan, literasi dan kesenangan. Terkait kebiasaan literasi baca tulis, media sosial dengan memberikan kemudahan dalam melakukan akses ke penyedia informasi, sehingga mahasiswa memanfaatkannya untuk memenuhi kebutuhan tanpa harus bersusah payah, terutama untuk membaca ulang dan memeriksa bahan bacaan. Ragam informasi yang terus berubah dengan cepat, membuat mahasiswa merasa
\end{abstract}


cukup membaca judul-judul berita tanpa harus membaca keseluruhan isi informasi yang ada. Demikian pula mengenai kredibilitas sumber berita, tidak menjadi hal yang penting untuk diperhatikan oleh mahasiswa. Ini menunjukkan bahwa kebiasaan menggunakan media sosial, belum dapat membantu meningkatkan kemampuan literasi di kalangan mahasiswa..

Kata kunci: Media Sosial, Literasi, Informasi Digital

\section{Pendahuluan}

Teknologi komunikasi telah memperluas jangkauan komunikasi melalui Teknologi Informasi dan Komunikasi (TIK). Kehadiran teknologi modern dalam komunikasi, telah mengubah dunia seseorang yang terbatas menjadi tanpa batas. Kehadiran teknologi ini memberikan dampak positif dan juga dampak yang negatif. Pada sisi positif, teknologi informasi membantu manusia menjadi lebih informative dan mengikuti perkembangan dunia.

Situs jejaring sosial seperti Twitter, Facebook, WhatsApp, Skype, Google talk, Google Messenger, Zoom, web portal berita dan web blog yang dapat diakses secara mudah, telah memperluas jaringan interaksi antar manusia dengan sangat mudah, baik dengan teman lama dan juga mendapatkan teman baru (Agwu dan Okoye, 2017). Penelitian lainnya menunjukkan bahwa banyak pelajar menggunakan jejaring media sosial untuk bersenang-senang, untuk menghabiskan waktu dan bertemu teman lama, atau mendapatkan teman baru (Yu Chen dan Starobin, 2019)

Kehadiran jejaring sosial ini telah mengubah dunia melalui evolusi teknologi, sebagai alat komunikasi terbaik. Dua pertiga dari pengguna internet dunia, aktif menggunakan jejaring sosial sebagai alat komunikasi, yang ingin berkomunikasi dengan pengguna lain tentang bidang minat bersama, baik dari perspektif pribadi, bisnis, atau akademik (William, Boyd, Densten, Chin, Diamond \& Morgenthaler 2009).

Evolusi teknologi ini telah menimbulkan dilema dalam peningkatan keterampilan generasi muda, seperti kemunduran nilai-nilai nyata kehidupan masyaratak terpelajar, terutama mahasiswa. Bagaimanapun, media sosial mash terfokus pada membangun dan mencerminkan asosiasi sosial di antara orang-orang yang memiliki minat dan atau aktivitas yang sama. Ini terlihat dari banyaknya group-group media sosial yang dibentuk untuk membahas berbagai persoalan yang disukai oleh setiap anggota group tersebut.

Semakin banyak group-group media sosial yang diikuti oleh seseorang, menunjukkan bahwa sangat banyak peminatan dan aktivitas yang ingin didapatkan oleh orang tersebut. Liccardi, Ounnas, Massey, Kinnunen, Midy \& Sakar (2007) menjelaskan bahwa pelajar secara sosial terhubung satu sama lain untuk berbagi pengalaman belajar sehari-hari dan melakukan percakapan tentang beberapa topik. Hal ini dapat berdampak pada kegiatan lain, seperti pekerjaan rumah dan waktu membaca yang semakin berkurang, karena mereka lebih banyak mengobrol melalui media sosial dengan teman. Olowu dan Seri (2012) mencatat bahwa banyak pelajar 
yang terhubung dengan media sosial hampir selama 24 jam online. Hasil pengamatan menunjukkan banyak pelajar sibuk berkomunikasi dengan media sosial, bahkan saat mengikuti kuliah yang sedang berlangsung.

Penggunaan media sosial juga telah mempengaruhi penggunaan tata bahasa para pelajar (Obi, Bulus, Adamu \& Sala'at 2012). Dalam berkomunikasi menggunakan ruang bercakap di media sosial, para pelajar terbiasa menulis kata-kata singkat bercampur antara penggunaan Bahasa Indonesia dan bahasa asing (Bahasa Inggris), dan seringkali menggunakan kebiasaan yang sama saat menulis tugas kuliah atau dalam tulisan formal lainnya.

Selain itu, hanya hanya sedikit pelajar yang menyadari bahwa media sosial juga memiliki peluang untuk pengembangan akademik dan keterampilan profesional. Media sosial belum dimanfaatkan oleh para pelajar untuk membangun pengalaman belajar dan kehidupan akademis mereka (Nugraha, 2017). Banyak penelitian yang mengungkapkan bahwa media sosial adalah aplikasi yang tidak aman bagi remaja. Trusov, Bucklin \& Pauwels (2009) mengungkapkan bahwa internet yang merupakan evolusi teknologi, sangat tidak aman bagi pelajar, karena media sosial memberikan kemudahan untuk menghubungkan orang satu sama lain; memposting berita, materi informatif dan hal-hal lain termasuk video dan gambar (Chester, Kienhuis, Pisani, Shahwan-Akl \& White, 2013) yang dapat diakses tanpa batas.

Meski demikian, media sosial telah diakui sebagai sumber penting dalam proses pendidikan saat ini. Apalagi sejak terjadinya Pandemi Covid-19 yang melanda seluruh dunia, aktivitas pembelajaran formal dan peningkatan keterampilan dilaksanakan berbasis internet. Sebagian besar kegiatan belajar mengajar telah dialihkan ke kelas daring dengan menggunakan aplikasi-aplikasi media sosial. Oleh karena itu, sangat penting untuk mengeksplorasi beberapa masalah yang sedang tren yang dihadapi di kalangan mahasiswa sebagai hasil dari media sosial.

Pada semua tingkat pembelajaran, pemanfaatan media sosial menjadi salah satu pilihan dalam meningkatkan kemampuan pelajar, termasuk di bidang pengembangan literasi di kalangan mahasiswa. Untuk itu masalah diteliti dalam penelitian ini adalah pemanfaatan media sosial dalam meningkatkan literasi di kalangan mahasiswa di Makassar. Penelitian ini bertujuan untuk menemukan peta pemanfaatan media sosial dalam membentuk budaya literasi di kalangan mahasiswa.

\section{Konsep Media Sosial}

Media sosial merupakan sarana yang menggunakan teknologi berbasis seluler dan web, yang dengan menghasilkan platform yang sangat interaktif sehingga individu maupun komunitas dapat berbagi informasi dan mendiskusikan suatu topik secara bersama-sama (Kietzmannn, 2012). Aplikasi media sosial memungkinkan setiap orang dapat melakukan pembuatan dan pertukaran konten yang yang dapat dipertukarkan atau digunakan bersama. Media sosial digunakan untuk saling berinteraksi antar-individu, menjalin hubungan kembali dengan teman lama dan menemukan teman-teman baru, tanpa dibatasi oleh jarak dan waktu. 
Dengan menggunakan aplikasi berbasis internet, media sosial memungkinkan penciptaan dan pertukaran konten yang dihasilkan pengguna (Anderson, 2019). Hal tersebut menyebabkan media sosial menjadi kanal utama dalam komunikasi antara lain melalui platform WhatsApp, Facebook, Line, Instagram, Twitter, dan sebagainya.

Boyd dan Ellison (2007) mendefinisikan jaringan media sosial sebagai layanan berbasis web yang memungkinkan individu untuk membangun profil, menampilkan koneksi pengguna, dan mencari dan melintasi dalam daftar koneksi tersebut. Media sosial adalah layanan atau platform online yang berfokus pada memfasilitasi pembangunan jaringan sosial di antara orang-orang yang memiliki minat, aktivitas, dan latar belakang yang sama pada hubungan di kehidupan nyata. Hal ini memungkinkan pengguna aplikasi media sosial untuk berbagi informasi dalam grup yang dipilih, dan menjadi pilihan untuk tetap terhubung dengan temanteman mereka (Osatuyi, 2013)).

Platform media sosial dapat memengaruhi cara pelajar terlibat dengan teknologi secara umum. Teknologi informasi telah melahirkan kelompok digital natives dan digital immigrants, yang dianggap sebagai representasi dalam memanfaatkan kemudahan, berdasarkan pada tingkat usia tertentu (Prensky, 2001). Prensky membedakan kedua kelompok itu dalam penggunaan teknologi, yaitu yang lahir sebelum tahun 1980 sebagai kelompok digital immigrants dan yang lahir setelah 1980 sebagai kelompok digital natives. Generasi muda yang merupakan digital natives, merupakan generasi yang sejak lahir telah dan lebih familiar dengan teknologi informasi, dan menginginkan informasi yang dapat diperoleh dengan cepat dan tepat (Himayah, 2013). Alih-alih membaca buku, mereka lebih banyak menghabiskan waktu mereka mengobrol dan berteman melalui media sosial dan berpengaruh pada kinerja akademis mereka. Sebuah tren dari survei di Amerika Serikat menunjukkan bahwa tahun 2006, sebanyak 37\% remaja online menggunakan media sosial, dan meningkat menjadi 555\% tiga tahun kemudian (Len Hart, dan Madden, 2007).

Pelajar menghabiskan lebih banyak waktu di media sosial seperti Facebook, Twitter, Instagram dan media sosial lainnya melalui smartphone. Mereka tidak ingin melakukan apapun sebelum memeriksa dan memperbarui profil mereka di jejaring sosial. (Morahan- Martin dan Schumacher, 2000) menjelaskan kecanduan media sosial sebagai penggunaan internet yang berlebihan dan kegagalan untuk mengontrol penggunaan smartphone membahayakan kehidupan seseorang. Lavuri, Navulla, dan Yamini, (2019) mengemukakan bahwa ada tingkat obsesi jejaring sosial yang mengkhawatirkan di kalangan pelajar saat ini, di mana sebuah tren dapat mempengaruhi kehidupan akademik, sosial dan spiritual mereka secara negatif jika tidak dikendalikan dengan baik.

Fenomena ini menjadi kekhawatiran banyak orang bahwa media sosial telah menghilangkan minat belajar dan mengembangkan keterampilan di kalangan generasi muda (McQuail 2008). Dalam studi terhadap 884 siswa dari berbagai universitas di Nigeria, diindikasikan bahwa siswa menghabiskan terlalu banyak waktu di situs jejaring sosial sehingga merugikan hal-hal lain yang diperlukan 
seperti studi mereka (Olowu \& Seri 2012). Kaum muda telah menjadikan media sosial sebagai prioritas utama mereka dan terus membutuhkan lebih banyak penggunaan agar merasa puas.

\section{Literasi dalam Media Sosial}

Di masa lalu, media dipandang sebagai penghambat dan tidak memberikan manfaat di bidang pendidikan. Karena itu banyak negara memblokir media sosial sebagai bentuk perlindungan kepada pelajar agar mereka tidak membuang-buang waktu, dan memberikan perlindungan privasi.

Keaksaraan di kalangan mahasiswa telah mengalami pemenurunan dalam dekade media sosial, terutama terkait kemampuan membaca, menulis, berbicara, dan berpikir, serta semua keterampilan paling dasar yang diperlukan untuk pengembangan literasi (Wise, 2009).

Kemudahan mendapatkan bahan bacaan dan copy paste, membuat mahasiswa menjadi tidak teliti dalam memanfaatkan bahan bacaan yang tersedia. Kemudahan pencarian bahan bacaan juga telah mengubah kebiasaan membaca di kalangan mahasiswa. Hanya dengan mengetikkan satu atau dua kata kunci melalui website mesin pencari, bahan yang dibutuhkan.Penerimaan informasi oleh individu, melewati tahapan sejak diterima dari sumber dan dapat mengalami perubahan makna dari orang yang berbeda, yang disebut sebagai komunikasi interpersonal (Supratman dan Mahadia, 2016).

Media sosial mendapatkan momentum di dunia informasi dan komunikasi, dan telah mengubah metode konvensional pengumpulan dan penyebaran berita, dab mengalami pergeseran paradigma dari media cetak dan penyiaran yang lebih efektif dan efisien. Masa pandemi Covid-19 yang melanda dunia sejak Desember 2019, juga telah memaksa masyarakat harus mengurangi interaksi secara langsung dan harus lebih banyak beraktivitas di rumah, serta menggantinya dengan berinteraksi secara dalam jaringan (daring). Keadaan tersebut memberi ruang kepada media sosial untuk meningkatkan manfaat dari sekadar saling mengobrol, menjadi media pembelajaran daring yang banyak digunakan sebagai pengganti ruang kelas.

Banyak sekolah menggunakan media sosial untuk menjalankan kegiatan belajar mengajar, membuat siswa tetap terhubung dengan tugas-tugas di sekolah (Boyd, 2007).

Pengembangan literasi digital dianggap sebagai peran lain yang menantang bagi universitas yang menawarkan kursus ilmu perpustakaan dan informasi untuk ilmuwan dan pengembang informasi di abad kedua puluh satu.

\section{Metode Penelitian}

Penelitian ini menggunakan pendekatan kuantitatif dan dianalisis dengan metode deskriptif. Data dikumpulkan melalui penyebaran angket melalui google docs di mana sumber data adalah mahasiswa pengguna media sosial aktif yang ada di Makassar. Sebanyak 200 responden dari berbagai perguruan tinggi di Makassar yang aktif menggunakan media sosial telah mengisi dan mengirimkan kembali angket. 
Data dianalisis dengan melihat frekuensi penggunaan media sosial untuk berbagai keperluan. Ada empat penggunaan yang media sosial yang diteliti dalam penelitian ini, baik terkait kebutuhan berkomunikasi, kesenangan, pendidikan dan keterampilan dan pemanfaatan untuk memperkaya literasi.

Komunikasi yang dimaksud dalam penelitian ini adalah kegiatan mengobrol yang dilakukan responden bersama teman-temannya. Sementara penggunaan media sosial untuk kesenangan adalah memainkan permainan dan mengembangkan hobbi. Yang dimaksud penggunaan media sosial untuk pendidikan dan keterampilan dalam penelitian ini terkait pembuatan tugas-tugas kuliah dan berinterkasi dengan dosen. Sedangkan pemenfaatan untuk memperkaya literasi bermakna responden memanfaatkan media sosial untuk membaca berita, melatih kemampuan mengolah informasi dan memahami bacaan-bacaan umum dan berdiskusi tentang permasalahan yang tidak terkait tugas kuliah.

Selanjutnya analisis dilakukan untuk mengetahui bagaimana tingkat pemanfaatan media sosial dalam meningkatkan literasi di kalangan mahasiswa.

\section{Hasil dan Pembahasan Penelitian}

Media sosial telah menjadi bagian utama dari kehidupan mahasiswa saat ini. Sebagian besar waktu sehari-hari dihabiskan dengan kegiatan yang meggunakan aplikasi media sosial melalui telepon pintar. Semua responden merupakan pengguna aktif media sosial dan selalu mengakses melalui jaringan internet setiap hari. Penggunaan media sosial ini terbagi untuk keperluan berkomunikasi, belajar dan meningkatkan keterampilan, mengembangkan hobbi dan mendapatkan kesenangan lainnya, ataupun mengakses berita dan mendapatkan bahan bacaan lainnya. Gambar 1 menjelaskan bagaimana penggunaan media sosial untuk setiap responden. Dari total akses media sosial yang dilakukan oleh responden, masih lebih banyak untuk keperluan mengobrol bersama teman-temannya, yaitu sebanyak $42 \%$. Ini menunjukkan bahwa responden benar-benar memanfaatkan media sosial untuk berhubungan dengan orang lain secara rutin dan saling berbagi informasi yang ada di sekeliling mereka.

Sementara itu, penggunaan untuk keperluan belajar meningkat sejak Pandemi Covid-19 karena mereka harus belajar dari rumah serta membuat tugas. Penggunaan media sosial untuk pendidikan menghabiskan waktu $29 \%$ dari total akses responden, baik untuk belajar secara online, melakukan konsultasi dengan dosen, membuat tugas kuliah dan menyerahkan tugas kuliah kepada dosennya.

Media sosial tidak terlalu digunakan untuk peningkatan literasi, yaitu hanya sebanyak 18\% dari total penggunaan media sosial tersebut. Sedangkan untuk kesenangan, tidak menjadi prioritas bagi responden, yaitu hanya $11 \%$. 


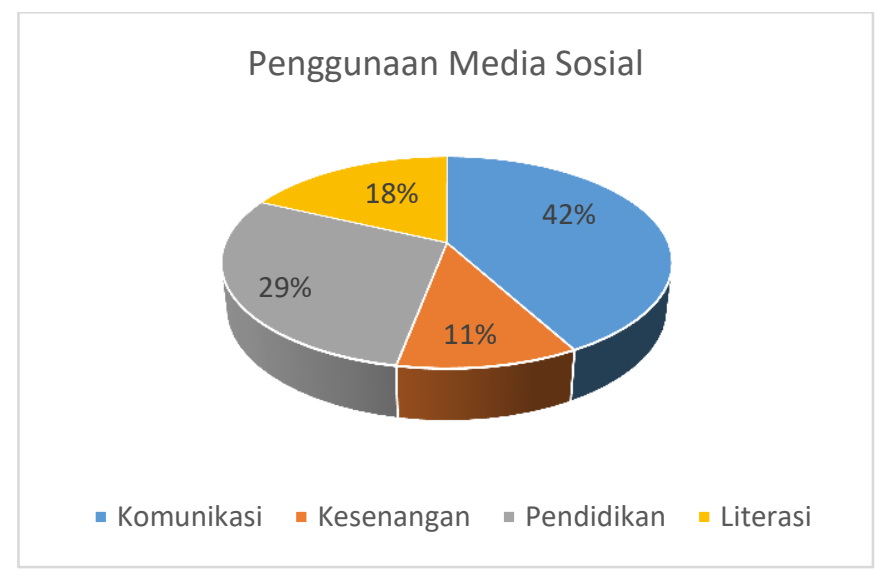

Gambar 1. Peta penggunaan media sosial rata-rata per responden

Semakin berkembangnya teknologi informasi, telah tercipta beragam aplikasi media sosial yang dapat diakses oleh masyarakat. Dari berbagai aplikasi media sosial yang tersedia, aplikasi mengobrol WhatsApp paling banyak diakses oleh responden. Gambar 2 menjelaskan pengggunaan media sosial di kalangan mahasiswa.

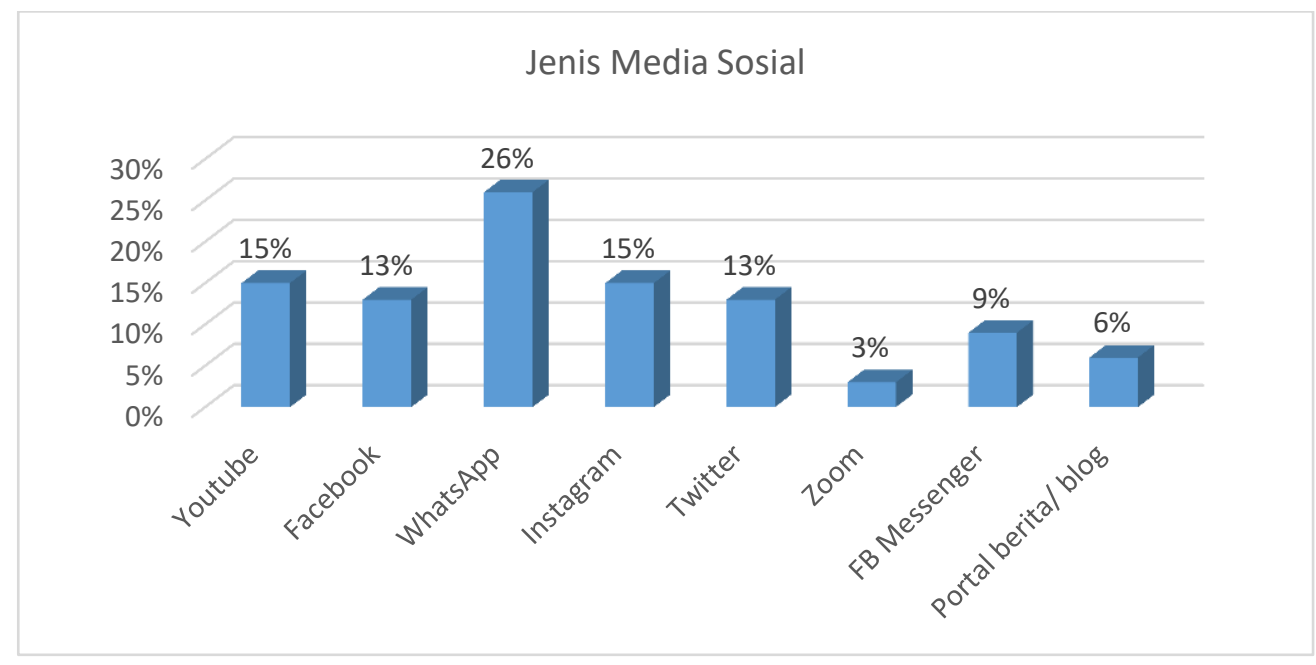

Gambar 3. Peta penggunaan jenis media sosial

Aplikasi pesan dan mengobrol seperti adalah yang paling banyak diakses oleh setiap responden. Aplikasi WhatsApp menjadi aplikasi yang sering digunakan, yaitu $26 \%$ dari total akses media sosial. Aplikasi ini memenuhi 
kebutuhan responden untuk saling mengobrol dan bertukar informasi dengan teman lama maupun teman baru serta mengobrol ramai-ramai dalam group. Sementara itu, aplikasi video Youtube dan Instagram juga banyak diakses, di mana rata-rata responden menggunakannya sebanyak masing-masing 15\% dari total kegiatan bermedia sosial mereka.

Akses ke jejaring sosial yang merupakan sumber berita dan informasi seperti web portal berita dan blog hanya mengambil porsi $6 \%$ dari total aktivitas media sosial responden. Sementara itu, aplikasi video chatting yang mengalami penggunaan pesat di masa pandemic Covid-19, juga diakses oleh responden, meski hanya rata-rata 3\% (Gambar 2).

Terkait kebiasaan literasi dalam penggunaan media sosial, responden pada umumnya memanfaatkan media sosial untuk mendapatkan berbagai macam informasi, karena sangat mudah diakses. Tabel 1 menjelaskan penggunaan media sosial dalam mendukung literasi di kalangan mahasiswa.

Tabel 1. Peta penggunaan media sosial dalam literasi

\begin{tabular}{|l|l|l|}
\hline No & Kegiatan & Nilai \\
\hline 1 & Membaca semua informasi tanpa menyaring & $95 \%$ \\
\hline 2 & $\begin{array}{l}\text { Melakukan penelusuran terhadap informasi yang } \\
\text { diterima }\end{array}$ & $21 \%$ \\
\hline 3 & $\begin{array}{l}\text { Mendiskusikan informasi yang tren dengan teman- } \\
\text { teman }\end{array}$ & $52 \%$ \\
\hline 4 & $\begin{array}{l}\text { Mencari dan mendapatkan bacaan-bacaan yang } \\
\text { disukai }\end{array}$ & $45 \%$ \\
\hline 5 & Mendapatkan bahan tugas kuliah & $100 \%$ \\
\hline 6 & $\begin{array}{l}\text { Membuka kamus digital untuk istilah yang kurang } \\
\text { dipahami }\end{array}$ & $11 \%$ \\
\hline 7 & $\begin{array}{l}\text { Ikut menyebarluaskan informasi yang menarik, } \\
\text { tanpa memperhatikan kredibilitas informasi yang } \\
\text { ada }\end{array}$ & $80 \%$ \\
\hline 8 & $\begin{array}{l}\text { Ikut menuliskan pendapat tentang informasi yang } \\
\text { sedang tren }\end{array}$ & $41 \%$ \\
\hline
\end{tabular}

Pada umumnye responden membaca semua informasi yang menarik yang ada di media sosial tanpa memperhatikan apakah informasi itu termasuk hoax atau berita yang benar. Ini terlihat bahwa 95\% responden mengatakan akan membaca semua informasi yang menarik, atau informasi yang sedang tren yang didapatkan dari media sosial. Tetapi hanya $21 \%$ yang melakukan penelurusan lebih lanjut terhadap informasi yang diterima. Sebanyak 52\% 
responden mengatakan, mereka sering mendiskusikan informasi-informasi itu bersama teman-temannya melalui aplikasi mengobrol.

Selain mendapatkan informasi yang sedang tren, banyak responden yang memanfaatkan media sosial untuk mendapatkan bahan bacaan yang mereka sukai, seperti cerita fiksi, tutorial dan lain sebagainya, yakni sebanyak 45\%. Namun semua atau 100\% responden mengatakan, tugas-tugas kuliah dan materi kuliah mereka dapatkan dengan mencari di jejaring sosial, terutama web mesin pencari. Sementara itu, banyaknya informasi yang beredar, seringkali menggunakan kata-kata atau istilah-istilah baru, terutama yang merupakan hasil adopsi dari bahasa lain. Namun hanya $11 \%$ responden yang mau repot untuk mencari arti sebenarnya dari istilah-istilah baru tersebut.

Banyaknya informasi menarik yang beredar di media sosial, seringkali dianggap penting oleh masyarakat untuk diketahui oleh lebih banyak orang, sehingga mereka ikut menyebarluaskan informasi tersebut. Keikutsertaan menyebarluaskan informasi yang ada, dilakukan oleh $80 \%$ responden. Sementara itu, hanya $42 \%$ responden untuk ikut menuliskan komentar mereka tentang informasi yang sedang tren.

Tabel 2. Peta Kebiasaan Literasi melalui Media Sosial

\begin{tabular}{|l|l|l|}
\hline No & Kebiasaan Literasi Baca Tulis & Nilai \\
\hline 1 & Membaca judul saja & $81 \%$ \\
\hline 2 & Membaca keseluruhan isi tulisan man kanal penyedia & $19 \%$ \\
\hline 3 & $\begin{array}{l}\text { Hanya membaca informasi dari ka } \\
\text { informasi yang kredibel }\end{array}$ & $6 \%$ \\
\hline 4 & Mencari informasi lain yang terkait & \\
\hline
\end{tabular}

Bahan bacaan yang beragam yang beredar di media sosial membuat banyak pilihan bagi masyarakat untuk mengakses informasi yang diinginkan. Responden penelitian ini mengungkapkan bahwa meski mereka membaca semua informasi yang ada, namun hanya sedikit yang benar-benar membaca seluruh isi informasi yang ada, sebagaimana ditunjukkan pada Tabel 1. Bahkan sebagian besar responden, yaitu sebanyak $81 \%$ menyatakan, mereka hanya membaca judul-judul saja, terutama berita-berita yang disajikan di web portal berita atau web blog. Hanya 19\% yang mau membaca keseluruhan isi informasi yang tersaji. Sementara itu, hanya sedikit responden, yaitu 10\% yang benar-benar menyaring informasi berdasarkan kredibilitas kanal web portal penyedia informasi. Hal ini menunjukkan bahwa kebiasaan menyerap informasi di kalangan mahasiswa tidak memiliki saringan, karena lebih memperhatikan konten berita daripada kredibilitas 
kanal penyedia informasi. Apalagi hanya 6\% yang benar-benar melakukan verifikasi informasi dengan mencari informasi-informasi serupa yang mungkin disediakan oleh kanal penyedia informasi lainnya.

\section{Kesimpulan}

Hasil dari temuan ini menunjukkan bahwa media sosial telah menjadi kebutuhan penting dalam kehidupan sehari-hari mahasiswa. Secara umum, media sosial lebih banyak digunakan untuk menghubungkan individu mahasiswa dengan temanteman mereka sebagai kebutuhan untuk berinteraksi satu sama lain. Hal tersebut ditunjukkan dalam kegiatan mengobrol yang mendominasi penggunaan media sosial. Sementara kemampuan literasi yang baik dengan menggunakan media sosial tidak menunjukkan peningkatan yang positif, melihat bahwa kemudahan mengakses informasi, menyalin dari sumber penyedia informasi dan menempel pada tugas-tugas yang dikerjakan, membuat mahasiswa tidak mau terlalu repot untuk membaca dan memperbaiki bahan informasi yang mereka dapatkan.

Ragam informasi yang tersedia dan mudah diakses serta informasi yang terus berubah dengan cepat dalam hitungan detik, membuat mahasiswa juga tidak mau bersusah payah untuk membaca keseluruhan isi informasi yang ada. Apalagi juduljudul informasi yang tersedia, terutama di web portal berita yang cukup panjang, seringkali sudah mengungkapkan isi berita itu sendiri. Demikian pula mengenai kredibilitas sumber berita, tidak menjadi hal yang penting untuk diperhatikan oleh mahasiswa. Bila informasi yang ada sudah ramai disebarluaskan melalui media sosial, biasanya telah dianggap sebagai informasi yang bisa diterima oleh masyarakat. Ini menunjukkan bahwa kebiasaan menggunakan media sosial, belum dapat membantu meningkatkan kemampuan literasi di kalangan mahasiswa

\section{Referensi}

Agwu, P. dan Okoye, U. (2017) Social media and insecurity of cultural values: Implications for social work practice in Nigeria. Conference: Presented at 2017 Interdisciplinary Research Conference, Ebonyi State University, Abakiliki on Poverty, Health and National Security.

Anderson, Terry (2019). Challenges and Opportunities for use of Social Media in Higher Education. Journal of learning for development. Vol. 6 no. 1 (2019): $\quad$ issue $1 . \quad$ Retrieved https://j14d.org/index.php/ej14d/article/view/327

Boyd, D. 2007. Why youth (heart) social network sites: The role of networked publics in teenage social life. MacArthur Foundation Series on Digital Learning-Youth, Identity, and Digital Media Volume. Cambridge, MA: MIT Press. 1-26.

Boyd, D. and Ellison, N. (2007). Social network sites: Definition, history, and scholarship. Journal of Computer-Mediated Communication, 13(1), 1-11. Retrieved from http://jcmc.indiana.edu/vol13/issue1/boyd.ellison.html. 
Chester, A., Kienhuis, M., Pisani, H., Shahwan-Akl, L., \& White, K. (2013). Professionalism in Student Online Social Networking: the role of educators. E-Learning and Digital Media Volume 10, Number 1, 2013 www.wwwords.co.uk/ELEA.

Himayah, H. (2013). Layanan dan Pelayanan Perpustakaan: Menjawab Tantangan Era Teknologi Informasi. Khizanah al-Hikmah: Jurnal Ilmu Perpustakaan, Informasi, dan Kearsipan, 1(1), 1-6.

Kietzmann, H. (2012). "Social media? Get serious! Understanding the functional building blocks of social media". Business Horizons 54: 241-251.

Lavuri, R., Navulla, D., \& Yamini, P. (2019). Effect of Social Media Networks on Academic Performance of Indian. Journal of Critical Reviews, Vol 6, Issue 4, p. 71-78

Lenhart, A., \& Madden, M. (2007). Teens, Privacy \& online social networks: How teens manage their online identities and personal information in the age of My Space. Washington, DC.

Liccardi, I., Ounnas, A., Pau, R., Massey, E., Kinnunen, P.Lewthwaite, S., Midy, A., \& Sakar, C. (2007). The role of social networks in students' learning experiences. ACM SIGCSE Bull 39(4), 224-237.

McQuail, D. (2008). Mass communication theory (5th ed). California: Sage Publishers.

Morahan-Martin, J., \& Schumacher, P. (2000). Incidence and correlates of pathological Internet use among college students. Computers in Human Behavior, 16, 13-29.

Nugraha, M.T (2017). Budaya Literasi Dan Pemanfaatan Sosial Media Pada Masyarakat Akademik. At-Turats Vol. 11 No.2 (2017) p. 124 - 132

Olowu, A. O., \& Seri, F. O. (2012). A study of social network addiction among youths in Nigeria. Journal of Social Science and Policy, Review 4, September 2012.

Osatuyi, B. (2013). Information sharing on social media sites. Computers in Human Behavior. Volume 29, Issue 6, November 2013, Pages 2622-2631

Prensky,M, On the Horizon (MCB University Press, vol.9 No.5, October 2001) Rapacki, S. (2007). Social networking sites: Why teens need places like myspace. Young Adult Library Services. 28-30.

Supratman, L.P., \& Mahadian, A.B. (2017) Psikologi Komunikasi, (Yogyakarta: Deepublish. 2016).

Trusov, M., Bucklin, R., \& Pauwels, K. (2009). Effects of word-of-mouth versus traditional marketing: Findings from an internet social networking site. Journal of Marketing, 73(5), 90-102.

Williams, A. Boyd, S. Densten, R. Chin, D. Diamond, and C. Morgenthaler, "Social Networking Privacy Behaviors and Risks", In Proceeding of CSIS Research Day, Seidenberg School of CSIS, Pace University, USA. 2009.

Wise, B. (2009). Adolescent literacy: The cornerstone of student success. Journal of Adolescent and Adult Literacy, 52, 369-375.

Yu Chen and Starobin, S. (2019) Formation of Social Capital for Community College Students: A Second-Order Confirmatory Factor Analysis. Community College Review 47(1):3-30 